\title{
FILOSOFIA, LÓGICA E DEMOCRACIA NO CONTEXTO DA EDUCAÇÃO
}

\section{ARTIGO DE REVISÃO}

FILHO, Augusto Gonçalves ${ }^{1}$

PINTO, João Rodrigues ${ }^{2}$

FILHO, Augusto Gonçalves. PINTO, João Rodrigues. Filosofia, Lógica e Democracia no Contexto da Educação. Revista Científica Multidisciplinar Núcleo do Conhecimento. Ano 04, Ed. 12, Vol. 03, pp. 05-12. Dezembro de 2019. ISSN: 24480959, Link de acesso: https://www.nucleodoconhecimento.com.br/educacao/filosofialogica

\section{RESUMO}

Este estudo traz uma reflexão crítica do caminhar da produção de saberes e o seu caráter prático, enquanto mediadora das práticas reais pautadas numa Filosofia de dimensão ética. Busca explicitar a representatividade da relação que permeia a educação e os paradoxos atribuídos ao processo do educar e a práxis na escola. Discute a mediação da filosofia no âmbito teórico-prático que possibilita o enfrentamento dos desafios da educação presentes na evolução da sociedade, com o intuito de efetivar o processo de formação do conhecimento, em sua completude e de forma ética, considerando os diversos posicionamentos de diversificadas áreas

${ }^{1}$ Mestrando em Ciências da Educação (Universidad Grendal), Especialista em Planejamento Educacional (UNIVERSO), Especialista em Cosmetologia Aplicada (Faculdades Oswaldo Cruz), Graduado em Química (UFSC).

2 Doutorado em Programa de Pós-graduação em Letras e Linguística. Mestrado em Artes Cênicas. Especialização em História do Brasil. Graduação em Letras. 
agregando valores ao saber a percepção e compreensão de si próprios e do mundo que o cerca.

Palavras-chave: Filosofia, educação, conhecimento, ética.

\section{INTRODUÇÃO}

"Na educação busca-se levar o indivíduo a aceitar voluntariamente as regras do jogo social, instruindo-o no conhecimento que o tornará um cidadão útil”. Rubem Alves

A filosofia é compreendida como ciência que cuida acerca da completude e profundidade que abrange as reflexões crítica dos indivíduos, com papel relevante no âmbito da educação. São diversos os aspectos, que oportunizam indagações reflexivas que contribuem para desenvolver o conhecimento, o senso crítico e agrega valores aos saberes diversos, através da percepção dos direcionamentos que permite a implementação de novos paradigmas e fundamentações.

Este artigo trata de uma abordagem crítica reflexiva com foco no contexto, que permeia a filosofia no âmbito educacional, enquanto instrumento mediador no fortalecimento da busca e desenvolvimento do conhecimento, nas pesquisas, na delineação da trajetória do saber por meio de suas indagações e propostas. Busca-se ampliar a compreensão e ressaltar a importância da filosofia na lógica investigativa, no pensamento reflexivo e crítico, bem como, na práxis do pensar[3].

\section{EDUCAÇÃO COMO PROCESSO INTRÍNSECO À VIDA}

Uma abordagem sobre o valor da Filosofia no contexto lógico e democrático da educação, em particular contrapondo-o a um modo, dominante, de exercer esse saber no âmago das discussões e argumentações com a finalidade de obter "verdades", conduz a uma reflexão crítica do caminhar da produção de saberes e o seu caráter prático, enquanto mediadora das práticas reais pautadas numa Filosofia de dimensão ética, avaliando as implicações nesse contexto[4]. 
Nesse singularismo se levantam indagações do porquê e para que ensina, como se produz conhecimento, como direcionar as discussões e fundamentar a estruturação dos argumentos. Além de se questionar o que é mais significante na Filosofia no contexto educacional e nas produções acadêmicas atuais.

Discute-se a Filosofia na educação como propulsora na busca de novas estratégias e fundamentações, para trabalhar o comportamento produtivo no âmbito acadêmico. Considera-se que, no geral o que é mais aceito, de modo natural no contexto social, filosoficamente, lógico e democrático, se torna mais problemático. Desse modo, somente na reflexão e análise do contraditório, é possível buscar sentido na indagação, na produção do discurso, na elaboração e avaliação dos argumentos, uma vez que, o saber somente esse vale a pena, porque emancipa e liberta[5].

O aprendizado consiste em um processo intrínseco à vida dos seres humanos, pertinente à condição da espécie. As civilizações se perpetuam através de novas gerações cujos integrantes não agregam somente uma memória genética; na mesma intensidade, pressupõe também uma memória cultural, resultante da condição, de cada novo integrante do grupo, que necessita recuperar a memória, inserindo-se no contexto sua cultura que impacta, influencia e também é influenciada pelo meio, propiciando reflexões que estimulam e provocam novos conhecimentos, consequentemente, contribuem no cenário da educação e na liberdade de discussão[6].

\section{EDUCAÇÃO E SOCIEDADE: ÉTICA, FILOSOFIA E COMPROMISSO COM O CONHECIMENTO}

A Filosofia e a Ética no processo da construção do conhecimento, na Educação, se configuram em fenômenos significativamente relevantes, fundamentando o aprendizado no processo do desenvolvimento social e de vida plenas dos seres humanos. Compreende-se que, as mudanças vivenciadas nas últimas décadas em toda a sociedade contemporânea, requer uma reflexão e uma releitura dos debates voltados para questões não somente pragmáticas, mas também, da consciência das diversidades nos vários níveis da sociedade, que cada vez mais, exige urgência de 
saberes e conhecimentos, promovendo à práxis educacionais técnicas, práticas, mecanicistas, relegando ao esquecimento orientações importantíssimas como os saberes filosóficos e éticos[7].

A realidade atual passa por transformações multifacetadas buscam novas estratégias e fundamentações, para trabalhar a eticidade do comportamento humano em todos os segmentos da sociedade. Desenvolver uma reflexão crítica do caminhar da verdade, oportunizando a mostra de todas as suas faces, sem minimizar ou amordaçar uma ou outra[8].

Uma boa reflexão requer lógica, democracia, honestidade intelectual, mesmo que seja necessário se despir das próprias ideias e conjecturas, se tornar capaz de argumenta em defesa do contraditório, para não correr o risco de viciar o debate configurando em transformá-la em um jogo de palavras sem direcionamento, esvaziando-se da finalidade de ressaltar a verdade e Ihe atribuir valor.

\section{UMA FILOSOFIA NA POSTURA PROGRAMÁTICA}

No decorrer da evolução antropológica do ser humano, cujo processo ocorreu, inicialmente de maneira espontânea, a partir da evolução dos costumes, da sociedade e da educação, muitos foram os ganhos e as perdas, no decorrer do tempo. Nessa trajetória, o abandono da Filosofia, configura entre as perdas. A educação é concebida como uma prática social com a finalidade de desenvolver no indivíduo o que pode ser aprendido dentre uma diversidade de saberes existentes em uma cultura, objetivando a formação de acordo com as necessidades e demandas da sociedade, na qual o sujeito se encontra inserido em determinado momento da trajetória histórica de seu próprio desenvolvimento[9].

Esse desenvolvimento requer parâmetros éticos, morais, lógicos, normativos, filosóficos e democráticos. Através desse desenvolvimento se prepara para o exercício consciente da cidadania, trabalhando, debatendo e argumentando com a ética e a lógica, através de seus projetos, pesquisas, estudos, debates, em que em sua maioria, trazem na essência o objetivo de transformar os cidadãos, em indivíduos 
conscientes, com habilidade e capacidade de interferir no ambiente em que estão inseridos, estimulando o desenvolvimento do senso crítico e da autonomia democrática[10].

Todo ser humano tem a necessidade de se aperfeiçoar constantemente, essencialmente na formação profissional. Hoje, vive-se na era da tecnologia, em que a ciência evolui de maneira dinâmica e suas aplicações inovam a cada dia mais, portanto, não se pode conceber que o ser humano se mantenha no decorrer de sua vida, somente com o que aprendeu em poucos anos, em um período que ainda encontrava-se amplamente imaturo[11].

O principal caminho para efetivar a formação deve ser permeado por discussões acerca de questões éticas, haja vista, que é no âmbito da discussão e do aprimoramento do conhecimento, através da argumentação que se encontram inúmeras possibilidades que demonstram evidências da ética, enquanto elemento necessário, lógico e fundamental, capaz de propiciar relacionamentos eficazes, democráticos, harmônicos e produtivos entre os diversos atores sociais[12].

No entanto, é notório, que as discussões e pesquisas, necessariamente, não poderão proporcionar todas as respostas às inúmeras indagações que são levantadas em seu âmbito, essencialmente, quando se reporta a questões de ética, lógica, filosófica e democrática, nem tampouco lhe cabe à responsabilidade de fracasso por não alcançar tal objetivo[13].

É necessário, contudo, persistir no seu papel de fomentar conhecimento. Como no discurso da Apologia de Sócrates citado por Lopes: "É provável que nenhum de nós saiba algo de valor, mas este crê saber e não sabe, enquanto eu, que efetivamente não e sei, tampouco creio (saber). Parece, pois que em um pequeno ponto sou mais sábio que ele: o que não sei, tampouco creio saber"[14].

Portanto, não se alcança o ápice do conhecimento, não se aprende tudo, pois ninguém sabe tudo, embora muitos possuam muitos saberes. É uma busca constante de aprendizado e de sentido, assim como a maneira de realizá-lo é a indagação de si e 
dos outros, uma vez que, todos têm algo a aprender. Assim, o educador, o pesquisador, o cientista, o pensador querem seja de Filosofia ou demais áreas do conhecimento não irão ensinar aos outros algo que não sabem[15].

Na realidade, é a própria busca que dá forma a uma prática que faz do ensino da ética e da moral ensinamentos que todos devem praticar e aprender, que são valores que se aprende com a Filosofia. Isso pode ser visto nos ensinamentos de diversos filósofos assim como Sócrates e outros estudiosos que afirmam para aprender o saber da ética, da moral, assim como o entender filosófico, é preciso acompanhar o caminho da reflexão, do conhecimento do mestre, conduzir-se por onde o outro já esteve deixarse orientar por aquele que sabe. Para aprender, é necessário de alguém que o conduza, que direcione, que bem sabe sobre aquilo que o indivíduo, de toda a maneira deve aprender[16].

Contudo, é necessário, ensinar e aprender, tendo como parâmetros norteadores à ética e os valores morais, que se encontram vinculados nas relações que se processam entre vários atores e os indivíduos nas suas ações com o outro, com a sociedade e com o mundo. A partir da Filosofia, que propõe reflexão e questionamento, busca-se construir um espaço de discussão, que possibilita ao docente e discente, partícipes do processo de ensino-aprendizagem a compreensão da ética como instrumento propulsor das atitudes morais. A Filosofia tem a incumbência de provocar rupturas no conhecimento simplista, comum, transportando o mundo estável do que se é familiar se coloque em movimentação.

Compreende-se que as arguições passam por uma transformação, que é aplicada ao cotidiano, a vivência do indivíduo, assim como também no âmbito dos relacionamentos, da vida em sociedade. Dessa maneira, a Filosofia configura-se em uma orientação, uma ferramenta que clarifica os pensamentos e as ideias utilizadas nas convivências diárias, nas apropriações do conhecimento e no seu aprimoramento através das arguições e discussões que provoca[17].

A atitude filosófica tem seu início no direcionamento das indagações sobre o universo que rodeia os indivíduos e as relações que são mantidas entre eles, pressupondo 
questionamentos que levam à necessidade de esclarecer a tendência do ser humano a interrogar o mundo e a si mesmo, na expectativa de conhecê-lo e conhecer-se[18].

\section{CONCLUSÃO}

É notório que as questões que se revestem de significância, na área das pesquisas que permeiam as ciências, se mostram complexas ao extremo. Nesse sentido não se pode compreender o processo de formação do conhecimento, na sua totalidade, se não se levar em consideração fatores relevantes que afetam o aprendizado e o desenvolvimento global, se não buscar respostas às indagações e não levar a cabo as discussões. Conclui-se, que seria significativo buscar a ruptura com a prática simplista de uma instrução fundamentalmente cognitiva, relacional, em uma discussão e argumentação paternalista e social. Todo o processo de ensino-aprendizagem, de desenvolver e aprofundar o estudo e o ensino resultaria em maior relevância educacional, sendo fundamentadas na prática filosófica, associando uma parcela de conceitos e conhecimentos e, outra de reflexão e arguições da relação com o mundo, atitudes, posicionamentos, ética, lógica e valores.

\section{REFERÊNCIAS}

ARANHA, Maria Lúcia de Arruda. Filosofia da educação, 2 ed. São Paulo: Moderna, 2002.

FREIRE, Paulo. Pedagogia da autonomia. 25 ed. São Paulo: Paz e Terra, 1996.

GAMBÔA, R. Educação, ética e democracia: a reconstrução da modernidade em John Dewey. Porto: Asa, 2004.

GÓMEZ, A. I. Pérez. A cultura escolar na sociedade neoliberal. Porto Alegre: Artmed, 2001.

KOZICKI, Katya. A política na perspectiva da filosofia da diferença. In: OLIVEIRA, Manfredo. et. al. (Orgs.). Filosofia política contemporânea. Petrópolis: Vozes, 2003 
LOPES, Daniel Rossi Nunes. O filósofo e o lobo: filosofia e retórica no Górgias de Platão/ Daniel Rossi Nunes Lopes. Campinas, SP: [s.n.], 2008.

MARCONDES, Danilo. Textos básicos de filosofia. 2 ed. Rio de Janeiro: Jorge Zahar, 2000.

SAVIANI, Dermeval. Educação: do senso comum à consciência filosófica. 18 ed. Campinas, SP: Autores Associados, 2009.

\section{APÊNDICE - REFERÊNCIAS DE NOTA DE RODAPÉ}

3. ARANHA, Maria Lúcia de Arruda. Filosofia da educação. 2 ed. São Paulo: Moderna, 2002.

4. GAMBÔA, R. Educação, ética e democracia: a reconstrução da modernidade em John Dewey. Porto: Asa, 2004.

5. FREIRE, Paulo. Pedagogia da autonomia. 25 ed. São Paulo: Paz e Terra, 1996.

6. GÓMEZ, A. I. Pérez. A cultura escolar na sociedade neoliberal. Porto Alegre: Artmed, 2001.

7. GAMBÔA, R. Educação, ética e democracia: a reconstrução da modernidade em John Dewey. Porto: Asa, 2004.

8. KOZICKI, Katya. A política na perspectiva da filosofia da diferença. In: OLIVEIRA, Manfredo. et. al.(orgs.). Filosofia política contemporânea. Petrópolis: Vozes, 2003.

9. SAVIANI, Dermeval. Educação: do senso comum à consciência filosófica. 18 ed. Campinas, SP: Autores Associados, 2009.

10. Idem Ibidem.

11. SAVIANI, Dermeval. Educação: do senso comum à consciência filosófica. 18 ed. Campinas, SP: Autores Associados, 2009. 
12. GÓMEZ, A. I. Pérez. A cultura escolar na sociedade neoliberal. Porto Alegre: Artmed, 2001.

13. GAMBÔA, R. Educação, ética e democracia: a reconstrução da modernidade em John Dewey. Porto: Asa, 2004.

14. LOPES, Daniel Rossi Nunes. O filósofo e o lobo: filosofia e retórica no Górgias de Platão. Campinas, SP: [s.n.], 2008, p. 17

15. Idem Ibidem.

16. MARCONDES, Danilo. Textos básicos de filosofia. 2. ed. Rio de Janeiro: Jorge Zahar, 2000.

17. ARANHA, Maria Lúcia de Arruda. Filosofia da educação, $2^{\mathrm{a}}$ ed. São Paulo: Moderna, 2002.

18. Idem Ibidem.

Enviado: Outubro, 2019.

Aprovado: Dezembro, 2019. 